\title{
Biofilm biodiversity presented by fluorescent in situ hybridisation
}

\author{
Mirela Wolf ${ }^{1, *}$ \\ ${ }^{1}$ Wroclaw University of Science and Technology, Faculty of Environmental Engineering, Department \\ of Sanitary Biology and Ecotechnology, Wybrzeze Wyspiańskiego 27, 50-370 Wroclaw, Poland
}

\begin{abstract}
Numerous microorganisms may be present in the water distribution system. This is associated with the imperfection of purification processes, or secondary water pollution. Not only it results in the deterioration of water quality parameters, but it also increases threat of epidemiological problems. The water that is biologically unstable creates ideal conditions for colonization of the microorganisms to the inner surface of pipelines which may form biofilm. The key issue, enabling prevention and control of the impact of the development of biofilms, is to assess the biodiversity of microbiocenosis. In order to obtain comprehensive characteristics of microorganisms communities on a particular substrate, it is necessary to combine several techniques. Further analysis using molecular biology methods are usually after traditional methods of assessing the microbiological quality of water. Standard methods do not reflect the actual species composition, because they are targeted at the bacteria that can be isolated and cultured in the laboratory. Conventional methods are capable of detecting less than $10 \%$ of the organisms in the sample. In order to study the biodiversity of organisms inhabiting a biofilm (apart from the conventional methods) analyses of the diversity of nucleic acids should be used. The first method could be the polymerase chain reaction (PCR) and denaturing gradient gel electrophoresis (DGGE). Another way may be fluorescence in situ hybridization, which allows to detect determined DNA sequence using specially labeled oligonucleotide probes. Visualization of the material is performed using a fluorescence microscope. The main purpose of this article is to present rapid and precise identification groups of microorganisms in their natural habitat in biofilm using fluorescent in situ hybridization method (FISH) . FISH method can be successfully used to visualize these microorganisms, which show difficulties in culturing, as well as to provide knowledge on the phylogenetic structure in different habitats. FISH technique allows the quantitative description of environmental samples.
\end{abstract}

\section{Introduction}

Microorganisms in the water supply systems primarily dwell (95\% of the total biomass) in the biofilm form. In water distribution systems, the space between the water and the pipe

*Corresponding author: mirela.wolf@pwr.edu.pl 
surface is the layer where organic matter is accumulated and microorganisms are settled. Then they multiplied to form biofilms. In this way, the environment for the organisms of different food preferences and oxygen is produced [1].

Mature biofilm is a complex structure comparable to the ecosystem. Microorganisms are suspended in the extracellular polymers (EPS), and the exchange of matter and genes occurs through an extensive system of Casals [2]. First disadvantage is the possibility of detachement and transfer of portions of a microbial biofilm to other parts of the network. Further problem is the possibility of long-term survival or proliferation of pathogens (e.g. Legionella sp.) in the structures of the biofilm, among others, because of the limited penetration of disinfectant. The complexity of a mature structure provides protection against disinfectants therefore a potential source of pathogens. A commonly used chlorine disinfection greatly reduce pathogens in the water, but despite of this process their presence in water is still evident [3]. An important aspect is to stimulate destruction processes of metals by microorganisms colonizing the biofim, in particular by their metabolites. Products of metabolism are retained in the EPS layer, which can cause local changes in the physico-chemical properties of materials inhabited by bacteria [4].

Relatively there is little information about the microorganisms biodiversity forming the biofilm in water distribution systems due to the difficult access to the samples. Observations based on laboratory models of distribution indicates that as the maturation of a biofilm, cell density is stabilizing, and the species diversity increases [5]. Premature biofilm surrounded by the EPS provides an excellent basis for the creation of multi-species biocenosis. The species composition of biological membranes is distinguished by a certain subclass of Proteobacteria, Actinobacteria, Firmicutes, Verrucomicrobia, Nitrospirae, Bacteriodetes whose existence depends on the material which made water supply network, the age of the biofilm and methods of disinfection. According to this it can be concluded that the biodiversity of bacteria in the biofilm can be resulted of biotic and abiotic factors in the drinking water distribution system [6].

Traditional methods of assessing the microbiological quality of water are usually just the first step of identifying microorganisms, which directs further analyses using molecular biology methods. The introduction of molecular biology techniques in order to assess the species composition provides information about the biodiversity of organisms forming growths in water supply network. The limited access to the sampling area is a great difficulty. Each distribution system is diverse in terms of bacterial flora. Each water supply system is characterized by its own species composition of microorganisms, so it is not possible to draw general conclusions about the biodiversity of the biofilm $[7,8]$. The use of molecular techniques based on the analysis of $16 \mathrm{~S}$ rRNA/rDNA will provide information about microorganisms, where a standard water analysis do not. One of those methods may be fluorescence in situ hybridization (FISH), which is now widely used to identify bacteria in their natural habitat [9].

The results of research concerning the formation of biofilm and their qualitative composition can be used in the selection of technical materials for the construction of various types of installations in contact with water and the design processes.

\section{FISH method}

FISH technique is based on hybridizing fluorescently labelled probe to ribosomal rRNA in permeabilized whole microbial cells. Probes are short DNA sequences (16-20 nucleotides) labelled with a fluorescent dye. These sequences are complementary to the $16 \mathrm{~S}$ rRNA bacteria sequence in bacterial cells. Due to this method microorganisms may be located and identified [10]. 
FISH analysis consists of the following steps:

1. fixation of biological material,

2. sample dehydration,

3. hybridization of the sample with a probe and washing,

4. microscopic observations,

5. bacteria identification and quantitation using advanced software [11].

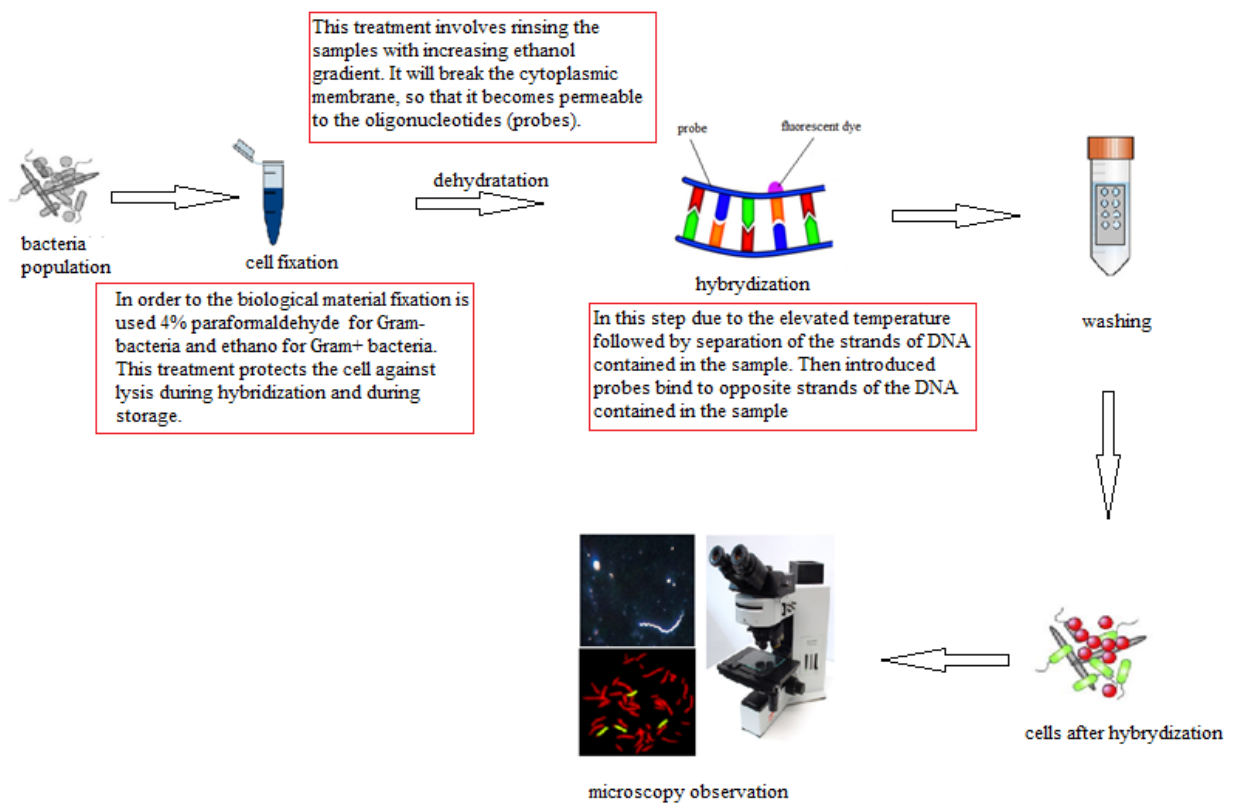

Fig. 1. Main steps of fluorescent in situ hybridization method [11, 12].

The main advantage of the FISH method is direct microorganisms visualization using the microscopy. It has higher sensitivity than the quantitative polymerase chain reaction (PCR) and is not prone to false results e.g. due to contamination with small amounts of DNA. Additionally, with PCR methods one can measure the number of copies of specific genes (not the number of cells), which may differ significantly from the number of particular organisms [12].

\subsection{Probes}

Microorganisms identification can be used by two probes: one characteristic of the group and second the specific. Simultaneous signal from two probes allows an assignment of the species and can eliminate misinterpretation. Examples of different probes are shown in Table 1 [13].

Depending on the size and use of the fluorescent probe is divided into:

$\checkmark$ whole chromosome painting (WCP)- covering all the selected chromosome, or specific arm; probe covers an area from several to millions base pairs,

$\checkmark$ centromeric enumeration probes (CEP)- specific to individual chromosomes, enable to identify the centromere; they reach a size of tens to thousands base pairs,

$\checkmark$ locus specific identifier (LSI)- complementary to a specific region of a chromosome centromere probes, their size are tens of thousands of base pairs and are visible on both chromosomes as well as in interphase [15]. 
Table 1. Examples of probe for fluorescent in situ hybridization [16].

\begin{tabular}{|c|c|c|}
\hline Short name & Specificity & Sequence from 5' to 3' \\
\hline ARC344 & Archaea & $\begin{array}{c}\text { TCG CGC CTG CTG } \\
\text { CIC CCC GT }\end{array}$ \\
\hline PLA46 & Planctomycetales & $\begin{array}{c}\text { GAC TTG CAT GCC } \\
\text { TAA TCC }\end{array}$ \\
\hline E11 & Eubacteria & $\begin{array}{c}\text { AGC CAT GCA GCA } \\
\text { CCT GTC TC }\end{array}$ \\
\hline DELTA495b & Deltaproteobacteria & $\begin{array}{c}\text { AGT TAG CCG GCG } \\
\text { CTT CCT }\end{array}$ \\
\hline UNIVER & all Bacteria & $\begin{array}{c}\text { CCG TMT TAC CGC } \\
\text { GGC TGC TGG CA }\end{array}$ \\
\hline
\end{tabular}

\subsection{Methodology}

A sample of the biofilm formed on the PCV material was fixed with $12 \%$ paraformaldehyde in buffered saline to give $4 \%$ as a final concentration of paraformaldehyde. Then it was incubated for 12 hours. The sample was concentrated on a filter with a $0.2 \mu \mathrm{m}$ pore diameter. The filter was washed with $5 \mathrm{ml}$ of sterile water and dried. Then to drain the sample, a number of alcohol dilution $(50 \%, 80 \%, 96 \%)$ was conducted $[11,14]$.

A filter was placed on a glass slide and covered with $50 \mu$ l of hybridization buffer $(\mathrm{NaCl}$, Tris-HCl, EDTA, SDS, formamide, probe) amount of each ingredient was depended on the type of the probe (Table 2). Incubation was conducted at $46{ }^{\circ} \mathrm{C}$ for 3 hours. Then it was incubated for 30 minutes with a washing solution at $48{ }^{\circ} \mathrm{C}(\mathrm{NaCl}$ changing concentration, Tris-HCl, EDTA, SDS). In order to visualize all living microorganisms in a sample was stained aqueous DAPI (4',6-diamidyno-2-fenyloindol) solution. The observation was performed by fluorescence microscopy [11, 14].

Probes sequences used to experiment are shown in Table 2.

Table 2. Sequences of probes used to identified different type of bacteria in fluorescent in situ hybridization [17].

\begin{tabular}{|c|c|l|l|c|}
\hline Name & $\begin{array}{l}\text { Sequence } \\
\text { from 5' to 3' }\end{array}$ & Type & $\begin{array}{l}\text { Formami- } \\
\text { de, \% }\end{array}$ & $\begin{array}{c}\mathrm{NaCl} \\
\text { in washing } \\
\text { buffer, } \\
\mathrm{mM}\end{array}$ \\
\hline BET42 & $\begin{array}{c}\text { CCTTCCCA } \\
\text { CTTCGTT }\end{array}$ & $\begin{array}{l}\text { Betaproteo } \\
\text {-bactea } \\
\text { class }\end{array}$ & 35 & 80 \\
\hline HGC69 & $\begin{array}{c}\text { ATATTACC } \\
\text { ACCGCCG }\end{array}$ & $\begin{array}{l}\text { Actinoba- } \\
\text { cteridae } \\
\text { class }\end{array}$ & 35 & 35 \\
\hline
\end{tabular}




\subsection{Results}

FISH method determines the total number of viable microorganisms in the test sample as well as a specific type or family of bacteria.

On the tested material bacteria with Actinobacteridae class- exhibited red color (8lighter areas), while Betaproteobacteria class showed- green color (10 lighter areas). All bacteria was shown using DAPI solution (25 blue lighter areas).
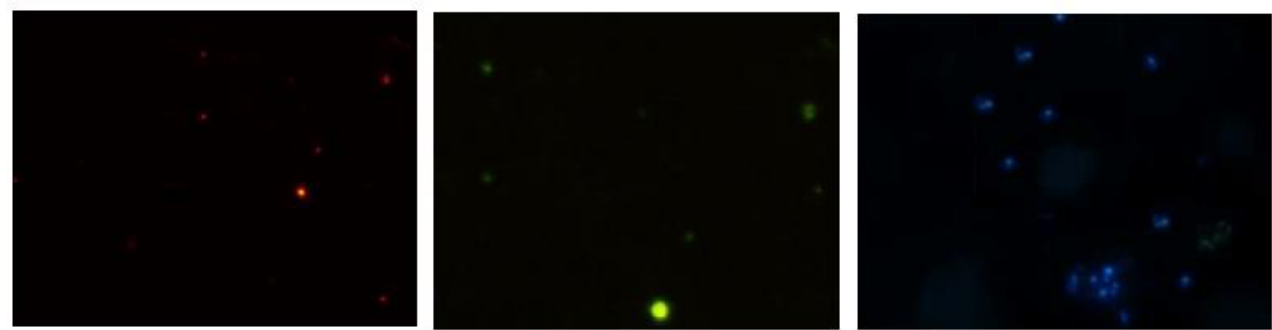

Fig.2. Example of visualisation bacteria in fluorescent microscopy after test measurement on fragment water distribution network made of polyvinyl chloride (lighter places- presence of bacteria), All alive cells-blue colour, Actinobacteridae class- red colour, Betaproteobacteria class- green colour.

\section{Conclusion}

Numerous microorganisms may be present in the water distribution system. This is associated with the imperfection of purification processes, or secondary water pollution. Not only it results in the deterioration of water quality parameters, but also increases threat of epidemiological problems.

FISH method can be used to visualize the microorganisms that cause problems in culture and also allows to know the structure of the phylogenetic groups in different habitats. The results of modern molecular methods often require more confirmation tests based on classical microbiology [18].

\section{References}

1. M. Lethola, K. Miettinen, M. Keinanen, T. Kekki, O. Laine, A. Hirvonen. Microbiology, chemistry and biofilm development in a pilot drinking water distribution system with copper and plastic pipes. Water Research, 38, strony 37693779 (2004)

2. M. Simoes, L. Simoes, M. Vieira M., A reviev of current and emergent biofilm control strtegies. Food Science and Technology. 4, 43, 573-583 (2003)

3. M. Batte, B. Appenzeller, D. Grandjean, S. Fass, V. Gauthier, F. Jorand, L. Mathieu, M. Boualam, S. Saby, J. Block, Biofilms in drinking water distribution systems. Reviews in Environmental Science and Biotechnology, 2, 147-168 (2003)

4. I. Neria-Gonzales, T. Wang, F. Ramirez, J. Romero, C. Hernandez-Rodrigues, Characterization of bacteria community associated to biofilms of corroded oil pipelines from the southeast of Mexico. Anaerobe. 12, 3, 122-133 (2006)

5. A.Grabińska-Łoniewska, E. Siński, Mikroorganizmy chorobotwórcze i potencjalnie chorobotwórcze $w$ ekosystemach wodnych $i$ sieciach wodociagowych. Warszawa: Seidel Przywecki (2010) 
6. L. Mathieu, C. Bouteleux, S. Fass, E. Angel, J. Block, Reversible shift in the alfa-, beta-, gamma- proteobacteria populations of drinking water biofilms during discontinous chlorination. Water Research, 56, 176-184 (2009)

7. D. Berry, C. Xi, L. Raskin, Microbial ecologyof drinking water distributions systems. Current Opinion in Biotechnology, 17, 297-302 (2006)

8. S. Nevel, K. Roy, N. Boon, Bacterial invasion potential in water is determined by nutrient availability and the indigenous community. FEMS Microbiology Ecology. 2013, Tom 85, strony 593-603.

9. B. Braun, I. Richert, U. Szewczyk, Detecton of ion- depositing Pedomicrobium in native biofilms from the Odertal NAtional Park by a new, species FISH probe. Journal of Microbiological Methods, 79, strony 37-43 (2009)

10. E.Valpi, J. Bridger, FISH glossary: an overview of the fluorescence in situ hybridization technique, BioTechniques, 45, 385-409 (2008)

11. P. Nielsen, D. Holger, H. Lemmer, I. Arslan-Alaton, T. Olmez-Hanci, FISH Handbook for Biological Wastewater Treatment. Identification and quantification of microorganisms in activated sludge and biofilms by FISH. London, IWA Publishing, 2009. 9781843392316 (2009)

12. B. Brehm-Stecher, E. Johnson, Single-Cell Microbiology: Tools, Technologies and Applications, Microbiology and Molecular Biology Reviews, 65, 538-559 (2006)

13. M. Jetten, L. Niftrik, M. Storus, B. Kartal, J. Keljtjens, Biochemistry and molecular biology of anammox bacteria. Critical Reviews in Biochemistry and Molecular Biology, 44, 65-84 (2009)

14. L. Sanz, T. Kochling, Molecuar biology techniques used in wastewater treatment: An overview, Process Biochemistry, 42, 119-133 (2007)

15. M. Fazli, T. Bjarnsholt, N. Høiby, M. Givskov, T. Tolker-Nielsen, PNA-Based Fluorescence In Situ Hybridization for Identification of Bacteria in Clinical Samples, Methods in Molecular Biology, 1211, 261-271 (2014)

16. T. Liehr, Classification of FISH probes, Part of the series Springer Protocols Handbooks, 43-47 (2016)

17. S. Boase, J. Jervis-Bardy, E. Cleland, H.Pant, L.Tan, Bacterial-induced epithelial damage promotes fungal biofilm formation in a sheep model of sinusitis, Allergy and Rhinology, 3, 341-348 (2013)

18. B.Bochner, L. Giovannetti, C. Viti, Important discoveries from analysing bacterial phenotypes, Molecular Microbiology, 70, 274-280 (2008) 